\title{
Atmospheric Water Monitoring by Using Ground-Based GPS during Heavy Rains Produced by TPV and SWV
}

\author{
Guoping Li ${ }^{1}$ and Jia Deng ${ }^{2}$ \\ ${ }^{1}$ College of Atmospheric Sciences, Chengdu University of Information Technology, Chengdu 610225, China \\ ${ }^{2}$ Meteorological Observatory of Sichuan Province, Chengdu 610072, China \\ Correspondence should be addressed to Guoping Li; leegp@126.com
}

Received 22 August 2013; Revised 13 October 2013; Accepted 14 October 2013

Academic Editor: Harry D. Kambezidis

Copyright (c) 2013 G. Li and J. Deng. This is an open access article distributed under the Creative Commons Attribution License, which permits unrestricted use, distribution, and reproduction in any medium, provided the original work is properly cited.

\begin{abstract}
The time series of precipitable water (PW) in 30 min intervals has been determined through experimentation and operational application of a ground-based global positioning system (GPS) network in Chengdu Plain, which is used for precise and reliable meteorological research. This study is the first to apply PW to the southwest vortex (SWV) and heavy rain events by using the data from an intensive SWV experiment conducted in summer 2010. The PW derived from the local ground-based GPS network was used in the monitoring and analysis of heavy rain caused by the SWV and the Tibetan Plateau vortex (TPV). Results indicate that an increase in GPS precipitable water (GPS-PW) occurs prior to the development of the TPV and SWV; rainfall occurs mainly during high levels of GPS-PW. The evolution features of GPS-PW in rainfall process caused by different weather systems over the Tibetan Plateau (TP) also differ. These results indicate the reference values for operational applications of GPS-PW data in shortterm forecasting and nowcasting of high-impact weather in addition to further investigation of heavy rain caused by the TPV, SWV, and other severe weather systems over the TP.
\end{abstract}

\section{Introduction}

Atmospheric water is a key factor in precipitation forecasting. The spatial and temporal distribution of this water and the latent heat generated by its phase transition play important roles in atmospheric water transport, energy conversion, and the evolution of weather by affecting atmospheric stability and the structure and changes of weather systems. Such factors are important in the formation of heavy rainfall events including vortices and storms.

The three states of water liquid, solid, and gas influence global positioning system (GPS) signals, which are used to determine the total atmospheric water content. Technology developed in the 1990s that uses GPS precipitable water (GPS$\mathrm{PW}$ ) to detect the atmospheric water content has high potential and practical value [1]. This method is used to determine water data for an entire day with high precision and temporal resolution, which is not possible by using conventional meteorological observations. Thus, the GPS-PW method is a practical improvement in the monitoring and forecasting capability of water vapor and precipitation $[2,3]$.
In recent years, local meteorological agencies in China, in conjunction with the departments of astronomy, earthquakes, surveying and mapping, investigation, and design, have developed numerous ground-based GPS meteorological networks based on various GPS meteorology and GPS-PW methods for data observation and weather forecasting [4-9].

Li et al. [10] were the first researchers to use GPS for remote sensing of atmospheric water in China. Sato and Kimura [11] studied the relationship between GPS-PW and convective rainfall. Okamura and Kimura [12] revealed the existence of GPS-PW variation after a cold front in the Kanto Plain, Japan. Liou and Huang [13] used GPS-PW data to analyze the weather processes affected by a passing typhoon. $\mathrm{Ha}$ et al. [14] compared GPS water observations with model simulations during the passage of a squall line. Most of these GPS-PW evolution studies determined that a high water value is necessary for producing precipitation. However, different processes of precipitation vary in the amplitude of the extreme value and the duration of GPS-PW. In addition to the aforementioned applications, GPS-PW data analysis has been applied to such processes as local convective rainfall [15], 


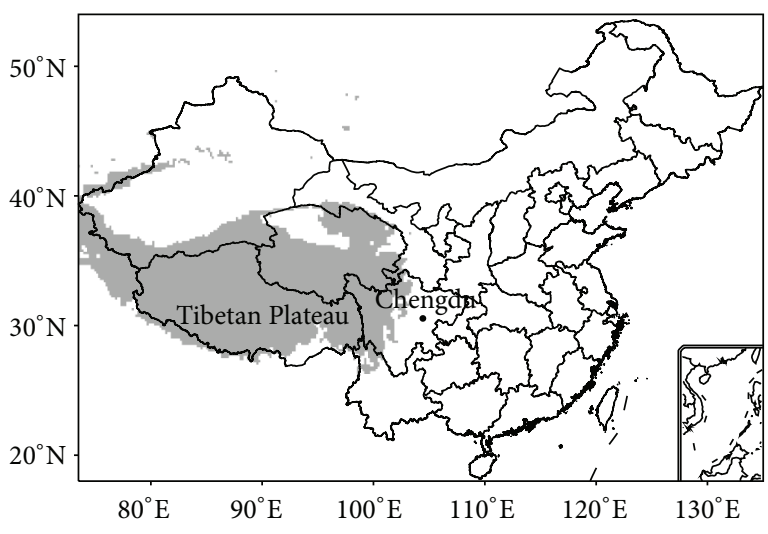

(a)

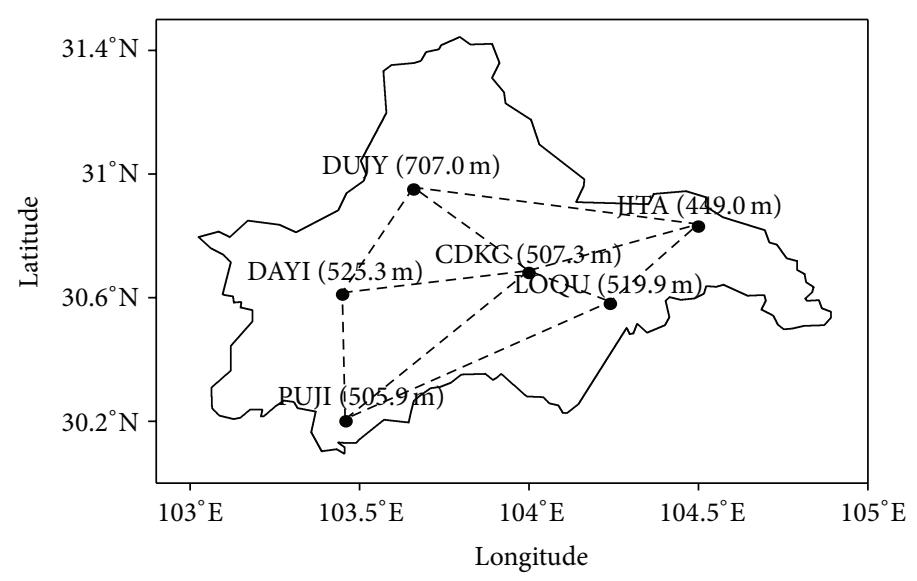

(b)

FIgure 1: (a) Geographical map of China. The small black dot represents Chengdu, and the shaded region represents the Tibetan Plateau with an altitude greater than $3000 \mathrm{~m}$. (b) Distribution of the GPS observation network in Chengdu Plain. Numbers in parentheses represent altitude.

fronts [12, 16-21], lightning [22, 23], thunderstorms [24], thermally induced local circulation [25-27], fog [28], snowfall [12], monsoons [29, 30], and other atmospheric wet phenomena [31]. All of these studies demonstrated the importance and the broad application prospects of GPS-PW remote sensing technology in the fields of weather forecasting and climate analysis. However, few studies thus far have used GPS-PW data to analyze heavy precipitation caused by the southwest vortex (SWV) and the Tibetan Plateau vortex (TPV), which is also known as the plateau vortex.

Meso- $\alpha$-scale low-level vortices that form near the Tibetan Plateau (TP) are among the most important rainproducing systems in China during the warm season. Several often migrate eastward from southwestern China to East China and develop into severe weather systems that cause flooding along their paths. Such vortex systems include the $\mathrm{TPV}$, which forms primarily at $500 \mathrm{hPa}$ on the TP, and the SWV, which forms primarily at $700 \mathrm{hPa}$ at the eastern flanks of the TP and the Sichuan Basin. The latter system was named as such by Chinese meteorologists because the vortices are located in southwestern China [32-35]. TPV and SWV research has previously focused on such factors as weather conditions, circulation, climate statistics, kinetic energy mechanism, diagnostic calculation, and numerical simulation $[36,37]$. Although it has since been determined that atmospheric water plays an important role in the formation and development of these vortices and their accompanying rainstorms [38, 39], GPS data has not been used thus far to reveal water variation in the development processes of the SWV. Therefore, the present study assumes the important task of using GPS remote sensing to reflect spatial and temporal variations of atmospheric water. The processes of heavy rain caused by the TPV and SWV occurring in September 2007, July 2008, and July 2010 in Chengdu Plain, southwestern China (Figure 1(a)), are comprehensively analyzed by using data from the GPS network in Chengdu Plain, located at the center of Sichuan Basin, combined with conventional meteorological observation data. Particular attention is given to the relationship between GPS-PW and the development of main influencing systems. This study is expected to provide new insight on the TPV, SWV, and related heavy rain events by establishing a new analytical technique for operational forecasting of vortex rainstorms.

\section{Principle, Methods, and Data}

The ground-based GPS observation network in Chengdu Plain, developed by the Surveying and Mapping Institute of Chengdu and the Meteorological Bureau of Chengdu, incorporates NetRS GPS receivers (Trimble, United States). The Meteorology Bureau of Chengdu has contracted the Huayun Company of China to build an automatic weather station (AWS) at the same site. The surface air pressure, surface air temperature, and precipitation were measured at the same AWS locations in which GPS observations were conducted. Enabled in September 2007, the ground-based GPS network (Figure 1(b)) in Chengdu, southwestern China, includes stations in Chengdu (CDKC), Dayi (DAYI), Longquanyi (LOQU), Jintang (JITA), Pujiang (PUJI), and Dujiangyan (DUJY), which are evenly distributed across Chengdu Plain. The longest baseline is from Pujiang to Longquanyi $(65 \mathrm{~km})$, and the shortest is from Longquanyi to Chengdu $(15.5 \mathrm{~km})$.

The zenith total delay (ZTD) was calculated by using Bernese GPS software V4.2 including raw data from the GPS observation network of Chengdu with a time interval of $30 \mathrm{~s}$ [40]. The zenith hydrostatic delay (ZHD) was calculated according to the Saastamoinen model [41]. Finally, GPS-PW was computed at $30 \mathrm{~min}$ intervals by combining ZHD and meteorological AWS data corresponding to the GPS stations.

National Centers for Environmental Prediction/National Center for Atmospheric Research (NCEP/NCAR) $1^{\circ} \times 1^{\circ}$ reanalysis data recorded four times daily in addition to data from conventional meteorological observation and an intensive SWV observation experiment conducted in summer 2010 were adopted in our comprehensive analysis of weather 
systems and the transfer of atmospheric water. The parameters of NCEP/NCAR reanalysis data used in this study include geopotential height $(500 \mathrm{hPa}$ and $700 \mathrm{hPa})$, wind, temperature, relative humidity, and vertical velocity from $850 \mathrm{hPa}$ to $200 \mathrm{hPa}$. The parameters of the intensive observation experiment used in this study include intensive radiosonde sounding such as wind, temperature, and relative humidity data recorded at each layer and intensive AWS observation of precipitation.

The basic procedure for deriving water from groundbased GPS is as follows: ZTD is first obtained from GPS observation and meteorological data at $30 \mathrm{~s}$ intervals. The Saastamoinen model is adapted for estimating ZHD such that $\mathrm{ZHD}=10^{-6}\left(k_{1} R p_{s} / g_{m} M_{d}\right)$. ZWD is obtained by the following formula: ZWD = ZTD - ZHD. The relationship between ZWD and PW is as follows: $\mathrm{PW}=\Pi \cdot \mathrm{ZWD}$ [1], where the conversion coefficient of water is a function of the mean weighted temperature $T_{m}: \Pi=\left(10^{6} / \rho_{w} R_{v}\left[\left(k_{3} / T_{m}\right)+k_{2}^{\prime}\right]\right) \cdot k_{1}, k_{2}^{\prime}$, and $k_{3}$ are refraction constants tested individually in a laboratory, and $T_{m}$ is the weighted mean tropospheric temperature. In this paper, local correction of the Bevis empirical formula established by Guo et al. [42] is adopted. Using 40 years of radiosonde sounding data recorded at eight stations in Sichuan and Chongqing, local models of the weighted mean tropospheric temperature are established by using the unitary linear regression method on the local surface and upper-air meteorological measurements. The local model for estimating $T_{m}$ in Chengdu Plain is $T_{m}=54.5+0.78 T_{s}$, where $T_{s}$ is the surface air temperature. Data from Dujiangyan station was not included is this analysis because its temporary relocation caused discontinuity in time and space data.

GPS remote sensing of atmospheric water has been compared with actual measurements at Chengdu by academic studies and by several global institutions for many years. Such research has demonstrated the feasibility of GPS water monitoring technology used in meteorological operations in Chengdu, which represents southwestern China. This new atmospheric sounding technology and its products have been applied in short-term forecasting and nowcasting. Software developed by Meteorological Information Comprehensive Analysis and Process System-China Meteorological Administration (MICAPS-CMA) has been applied to weather forecasting and determination of GPS water, real-time transmission of ground-based GPS observation data, data calculation, resolution of precipitable water, and the graphic display of GPS-PW products. The monitoring of GPS water and its products in weather analysis and forecasting was first conducted by Li et al. [15].

\section{Weather Applications}

\subsection{GPS-PW Applied to Analysis of Heavy Rain Caused by TPV}

3.1.1. Overview of Weather. A low-intensity and long duration rain event affected by the eastward shift of the TPV occurred on September 6-9, 2007, in Sichuan Basin leeward of the TP. The overall circulation was east high and west low on

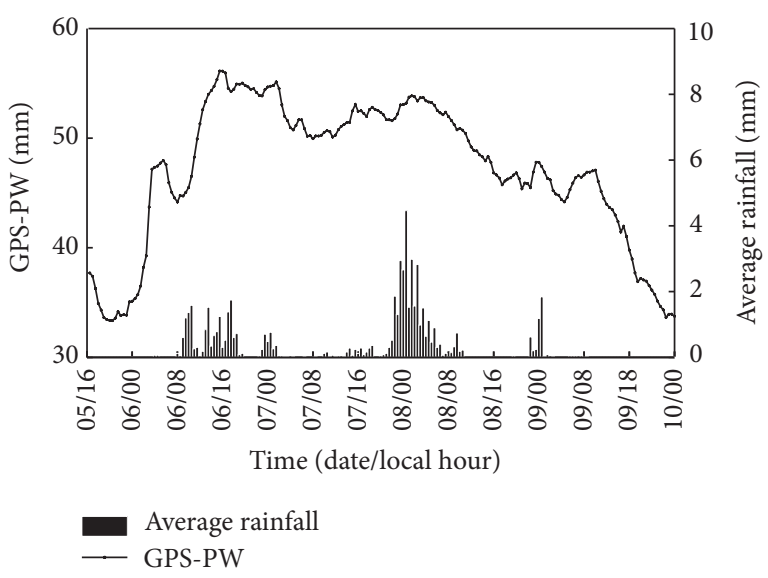

Figure 2: Temporal series of the average value of GPS-PW and regional average precipitation recorded on September 6-9, 2007, in Chengdu Plain. Stations include Chengdu, Dayi, Jintang, Pujiang, and Longquanyi.

the $500 \mathrm{hPa}$ height field (figure not shown). At 08:00 Beijing Standard Time (BST) on September 6, the TPV was generated in the western $\mathrm{TP}\left(34.8^{\circ} \mathrm{N}, 85^{\circ} \mathrm{E}\right)$. The ridge of high pressure located at $98^{\circ} \mathrm{E}$ controlled conditions in the eastern TP. At 02:00 on September 7, the TPV shifted to the eastern TP $\left(35^{\circ} \mathrm{N}, 96^{\circ} \mathrm{E}\right)$. At 14:00 on the same day, it moved out of the TP and was reduced to a short-wave trough. This precipitation was caused by the eastward movement of the TPV, which occurred mainly in the western Sichuan Basin. Rainfall recorded at each station exceeded $30 \mathrm{~mm}$; that at Pujiang station reached $92.7 \mathrm{~mm}$.

\subsubsection{Relationship between GPS-PW and Rainfall during} the Period of TPV. To determine the hourly evolution of atmospheric water during heavy rain events, the relationship between the average value of GPS-PW and the regional average precipitation in the Chengdu area was examined after averaging the GPS-PW of Chengdu, Dayi, Jintang, Pujiang, and Longquanyi. These stations were selected on the basis of geographical location to represent various characteristics of GPS-PW data.

As shown in Figure 2, the increase and decrease of GPSPW generally indicate the occurrence and end of rain events. Precipitation was measured by using AWS rain gauges. In this figure, the regional average precipitation and average GPSPW were determined using values measured at Chengdu, Dayi, Jintang, Pujiang, and Longquanyi stations. Approximately $12 \mathrm{~h}$ prior to the rain event, GPS-PW increased from $33.34 \mathrm{~mm}$ at 20:00 on September 5 to $47.95 \mathrm{~mm}$ at 05:00 on September 6 before slightly decreasing. At 15:30 on September 6, the GPS-PW rose to $56.11 \mathrm{~mm}$ as precipitation began. The GPS-PW at that stage was maintained at a relatively stable high value of approximately $50 \mathrm{~mm}$ and exhibited a slight fluctuation, whereas rain occurred during the second stage at 8:00 on September 7. At 00:00 on September 8, the average rainy intensity at each station increased by $4.46 \mathrm{~mm}$ every $30 \mathrm{~min}$; however, the average value of GPS-PW showed no 


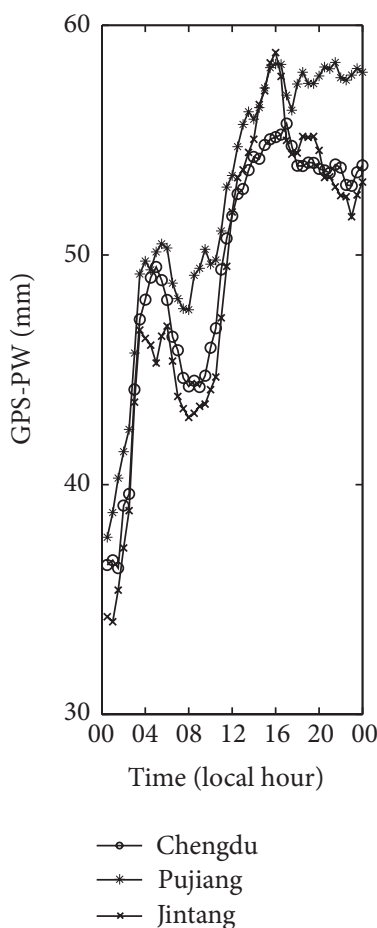

(a)

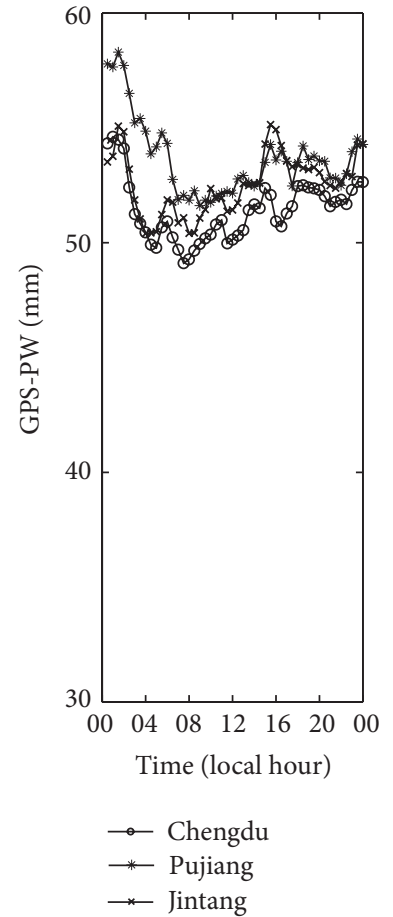

(b)

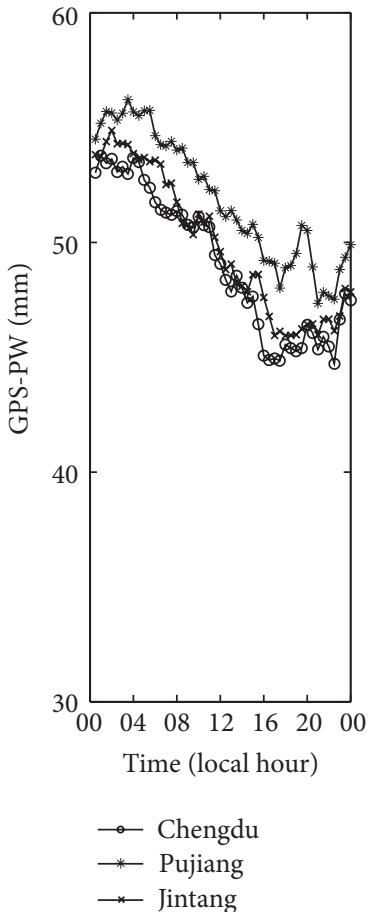

(c)

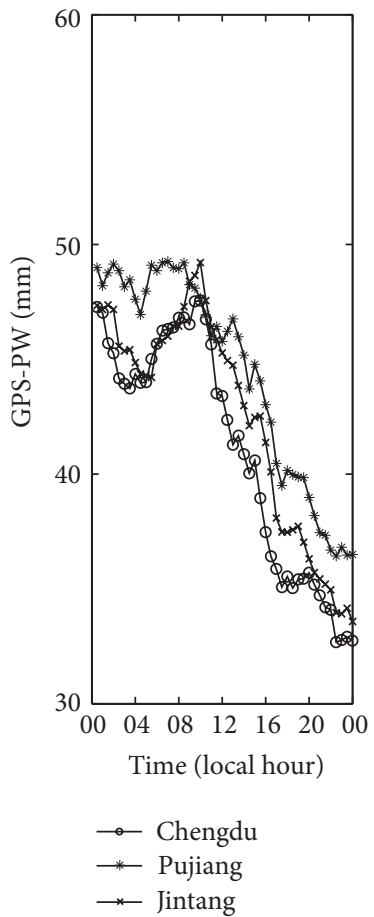

(d)

FIGURE 3: GPS-PW values recorded by Chengdu, Jintang, and Pujiang on September (a) 6, (b) 7, (c) 8, and (d) 9, 2007.

apparent change. The maximum value of average rainfall was noted prior to or at nearly the same time as the occurrence of the GPS-PW peak value. After 10:00 on September 9, the GPS-PW value decreased rapidly, and the rain event ended.

Although these results indicate that rain generally occurred during the period in which GPS-PW values were high and ended when values were low, such behavior is not definitive. As shown in Figure 2, the opposite also can exist. Thus, it is necessary to examine additional TPV periods to draw conclusions that are more realistic.

Figure 3 shows that high values of GPS-PW were mainly distributed in two periods from noon to nighttime on September 6 and from nighttime on September 7 to the morning of September 8, which corresponds with the two stages of precipitation. Prior to the rainfall, the atmospheric water content in the entire layer increased. Although the GPSPW value decreased after the first stage of rainfall, it maintained a high level. The water accumulated again, and the second stage of rainfall began when the GPS-PW value reached a new high. In contrast with the diurnal variation of GPS-PW in Chengdu, Pujiang, and Jintang, the diurnal cycle characteristics of GPS-PW in these stations were essentially the same. The values changed significantly during the day and were relatively stable at night during the major period of TPV from September 6 to September 8; however, that at Pujiang station was higher.

3.1.3. Relationship between GPS-PW and Physical Element Fields. As shown in Figure 4, Pujiang and Jintang stations, located, respectively, in the southwestern and northeastern
Chengdu Plain, recorded contrasting values. Prior to the rainfall at 02:00 on September 6, the water vapor flux was small in the $850 \mathrm{hPa}$ layer, and Chengdu Plain was relatively dry. In the flux field, water vapor transferred from south to north, intersecting in the eastern TP. The water vapor transferred to western Sichuan from the Bay of Bengal, and rain fell from 14:00 to 20:00 on September 6. The water vapor transfer was greater than $5 \mathrm{~g} \cdot \mathrm{cm}^{-1} \cdot \mathrm{hPa}^{-1} \cdot \mathrm{s}^{-1}$ in the $700 \mathrm{hPa}$ layer, the high-value area of water vapor transfer expanded, and the GPS-PW increased. At 08:00 on September 8, the water vapor transfer in the $850 \mathrm{hPa}$ layer was greater than $9 \mathrm{~g} \cdot \mathrm{cm}^{-1} \cdot \mathrm{hPa}{ }^{-1} \cdot \mathrm{s}^{-1}$ and was thus replenished. Chengdu Plain was relatively wet; the GPS-PW value was maintained at a high level, which was conducive to the reoccurrence of rainfall. The two high-value stages of GPS-PW were relative to the growth of regional water vapor transfer; however, the peak value of GPS-PW occurred earlier than that of the water vapor transfer for approximately $5 \mathrm{~h}$ to $7 \mathrm{~h}$.

In this process of rainfall, which was caused by eastward movement of the TPV, the water vapor increase was due mainly to the transport and the convergence of water vapor in the lower layer. As shown in Figure 5, the vortex center at $34.8^{\circ} \mathrm{N}, 85^{\circ} \mathrm{E}$ was ascending, and the maximum GPS-PW value $\left(5 \times 10^{-1} \mathrm{hPa} \cdot \mathrm{s}^{-1}\right)$ located in the $400 \mathrm{hPa}$ layer at 08:00 on September 6 was ascending correspondingly. At 02:00, the maximum vertical velocity was located at $500 \mathrm{hPa}$ with the same intensity. At 14:00 on September 7, the vortex began to move eastward, the vertical velocity decreased in the low layer, and the intensity of convergence weakened. The vortex then affected Sichuan Basin and moved out of the TP to form 


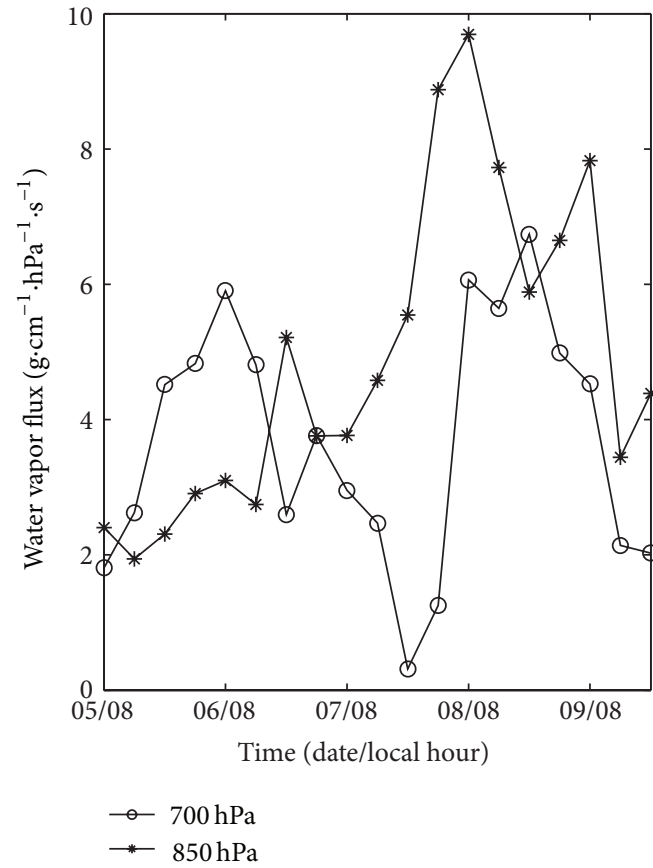

(a)

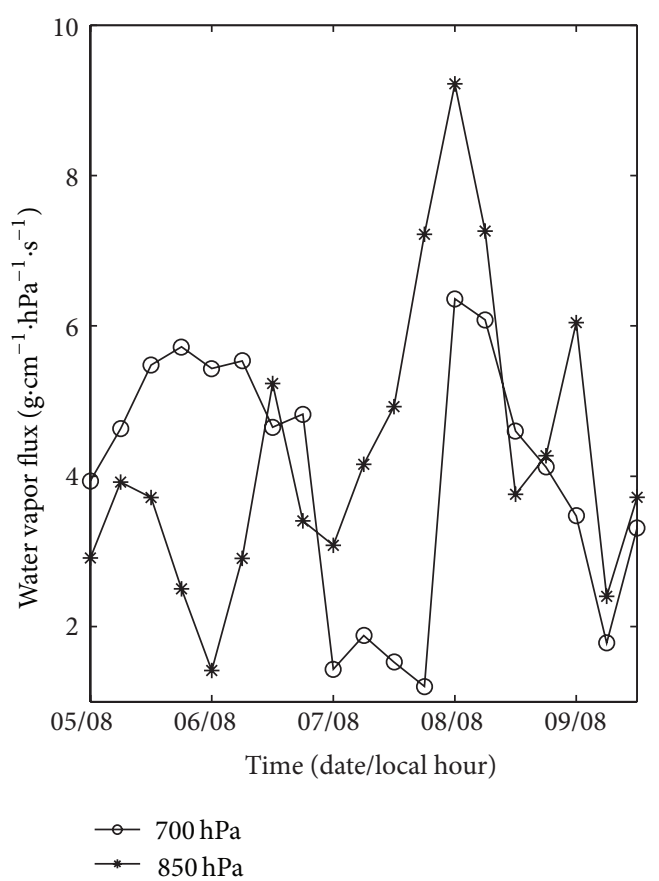

(b)

Figure 4: Evolution of water vapor flux recorded in September 6-9, 2007, at (a) Pujiang and (b) Jintang stations $\left(\right.$ unit: $\mathrm{g} \cdot \mathrm{cm}^{-1} \cdot \mathrm{hPa} \mathrm{a}^{-1} \cdot \mathrm{s}^{-1}$ ).

strong convergence over the entire Chengdu Plain (figure not shown). This result indicates that the vertical motion ascended, descended, and ascended from its generation to its movement away from the TP, which corresponds strongly with the increasing-decreasing-increasing variations of the GPS-PW (Figure 3). The GPS-PW began to increase rapidly for approximately $12 \mathrm{~h}$ prior to the vortex development before consistently changing with the intensity of the water vapor flux in the vortex center. In this case, a stronger water flux corresponded with a higher GPS-PW value.

\subsection{Application of GPS-PW to Analysis of Heavy Rain Caused by SWV}

3.2.1. Background of Weather. Because of the low-level jet from Nanhai and the invasion of northern cold air, combined with the long duration of the SWV in Sichuan Basin, heavy rain occurred in the northeastern Sichuan Basin on July 15-18, 2010. This rainfall event was of high intensity and long duration, and the precipitation measured at each station exceeded $20 \mathrm{~mm}$. At Pujiang station, it reached $95.4 \mathrm{~mm}$; the maximum $1 \mathrm{~h}$ rainfall was $33.8 \mathrm{~mm}$.

\subsubsection{Relationship between GPS-PW and Rainfall during} Period of $S W V$. Changes in the average GPS-PW value recorded at Chengdu, Dayi, Pujiang, and Longquanyi stations clearly show that this rainfall process can be divided into two stages: during the nighttime on July 15 and from nighttime on July 16 to the morning of July 17 (Figure 6). Approximately $6 \mathrm{~h}$ prior to the rainfall, the GPS-PW began to increase sharply and reached its first maximum value at 15:00 on July 15 . The GPS-PW value fluctuated slightly when the rain began. However, the peak of rainfall and that of GPS-PW did not always coincide. When the atmospheric water condensed in the form of rain and fell to the ground, GPS-PW clearly decreased. At 12:00 on July 16, GPS-PW surged again and reached its maximum value of $57.45 \mathrm{~mm}$ at 23:00 on July 16 . The second stage of rainfall occurred during this GPS-PW surge. The average rainfall was heavier than that recorded during the first stage; however, the peak of rainfall occurred approximately 4 h earlier than that of the GPS-PW. As shown in Figure 7, the GPS-PW recorded at each station reached maximum values at 00:00 on July 17; within $1 \mathrm{~h}$, the maximum rainfall and GPSPW were consistent with the distribution of the high value of GPS-PW. The peak value of GPS-PW during the second stage was greater than that during the first stage, and greater increases in amplitude of GPS-PW correlated with heavier rainfall. The oscillation change of GPS-PW was clear during this process; the changes in Chengdu and Pujiang stations were nearly the same; and the increase and decrease were largest at Dayi station. These results indicate that the convective instability of this rainfall was remarkable; no distinct diurnal cycle was observed at any station.

3.2.3. Contrast of GPS-PW and Physical Element Fields. Because the radiosonde station in southwestern China is unreliable in calculating the water vapor flux and the reanalysis data reasonably represents the atmospheric water in this region [43], the latter is generally used to evaluate this flux. As shown in Figure 8, Pujiang and Chengdu stations showed high values of water vapor flux from 02:00 to 20:00 


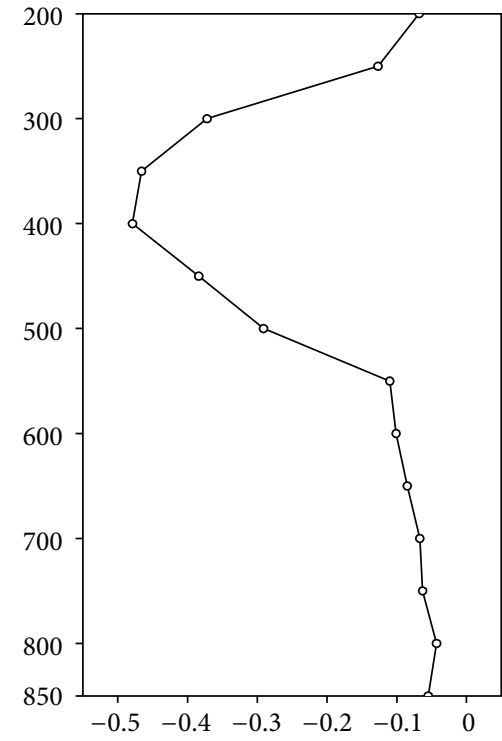

(a)

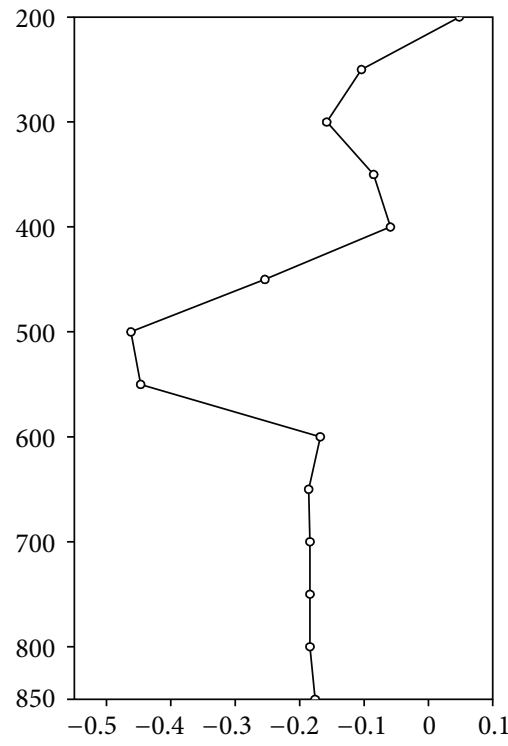

(b)

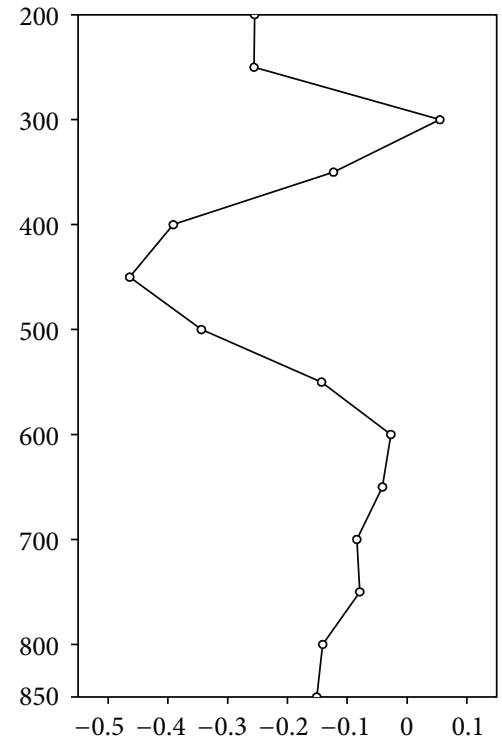

(c)

FIGURE 5: Profiles of the vertical velocity at the TPV center recorded at various times. (a) 08:00 Beijing standard time on September 6, (b) 02:00 on September 7, and (c) 14:00 on September 7, 2007 (unit: $\mathrm{hPa} \cdot \mathrm{s}^{-1}$ ).

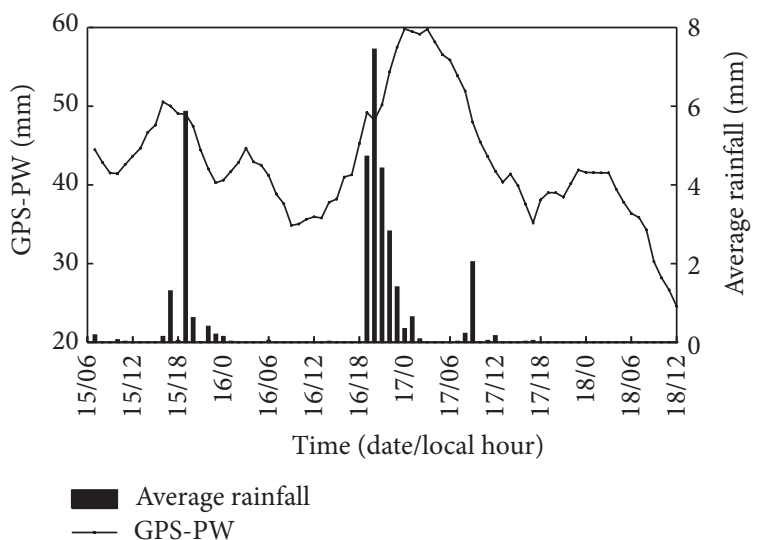

FIGURE 6: Temporal series of the average value of GPS-PW and regional average precipitation recorded on July 15-18, 2010, in Chengdu Plain at Chengdu, Dayi, Jintang, Pujiang, and Longquanyi stations.

on July 17 , which coincided with the period of SWV stagnation. With the strengthening of the low-level jet in the southeastern SWV, the maximum value of water vapor flux field $\left(21 \mathrm{~g} \cdot \mathrm{cm}^{-1} \cdot \mathrm{hPa}^{-1} \cdot \mathrm{s}^{-1}\right)$ at $700 \mathrm{hPa}$ at Pujiang station appeared at 14:00 on July 17 . The peak of GPS-PW occurred approximately $6 \mathrm{~h}$ earlier than that of the water vapor flux. Figure 9 shows a profile of the vertical velocity of the center of the TPV at various times along the center of the SWV. At 20:00 on July 16 , the SWV began to form. The vertical velocity of the vortex center at $30^{\circ} \mathrm{N}, 101^{\circ} \mathrm{E}$ ascended below $600 \mathrm{hPa}$ and descended between $600 \mathrm{hPa}$ and $300 \mathrm{hPa}$ layer as the GPS-PW value ascended. At 08:00 on July 17, which was the stagnant period of the vortex, the vertical velocity of the SWV center abruptly ascended from low to high levels, and the convective motion reached its peak. At 20:00, the vortex began to move eastward to Sichuan Basin $\left(31^{\circ} \mathrm{N}, 106^{\circ} \mathrm{E}\right)$, and the ascending motion weakened and finally descended. At the same time, the GPS-PW dropped to a low value, which was evident before moving eastward of the vortex. The GPS-PW clearly began to surge approximately $8 \mathrm{~h}$ earlier than the vortex development, and the maximum value occurred prior to the peak of the ascending motion of the vortex center. Continuous airflow and water convergence strongly influenced rainfall in the basin.

\subsection{Application of GPS-PW in Analysis of Heavy Rain Caused by TPV and SWV}

3.3.1. Weather Analysis. A regional rainstorm occurred from west to east in Sichuan Basin on July 20-22, 2008, in which the unevenly distributed rainfall was mainly located in the western basin. The rain was first observed at Chengdu station at 11:30 on July 20 and finally observed at Dayi station at 22:00 on July 21 . The main rainfall occurred at noon and during the nighttime on July 20. The interaction of the TPV and SWV triggered the strong development of the southwesterly lowlevel jet. The rain caused by the TPV was not apparent in the absence of the SWV. However, the SWV was induced with the eastward movement of the TPV. The interaction and development of these two vortices related to TP caused the heavy rain event in a large area of southwestern China.

\subsubsection{Relationship between GPS-PW and Rainfall during} Periods of TPV and $S W V$. As shown in Figure 10, a high GPSPW level of $50 \mathrm{~mm}$ caused by the TPV formed in the eastern plateau prior to rainfall. At 07:00 on July 20, the GPS-PW 


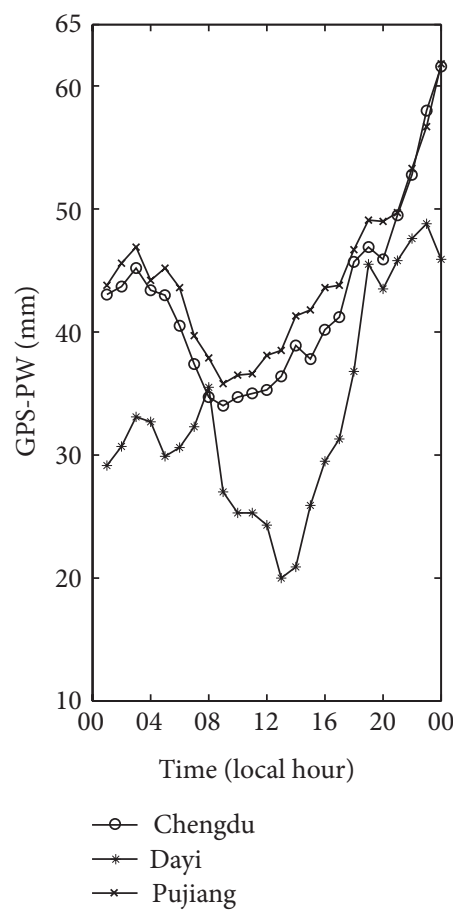

(a)

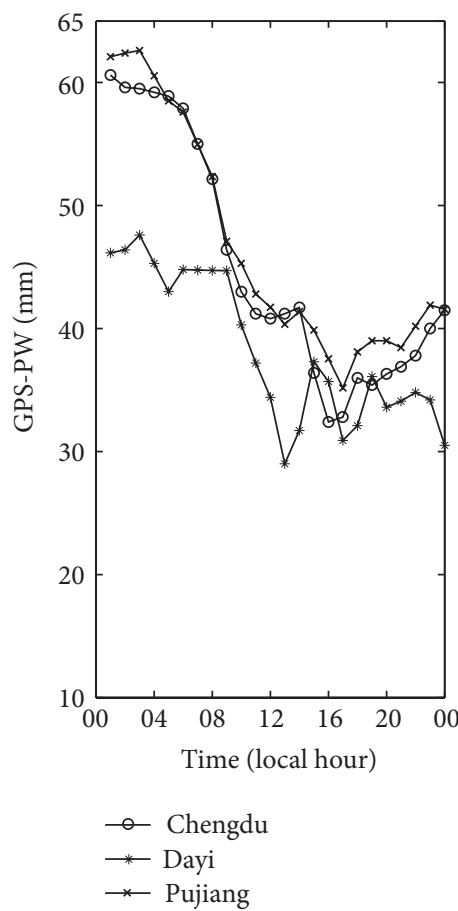

(b)

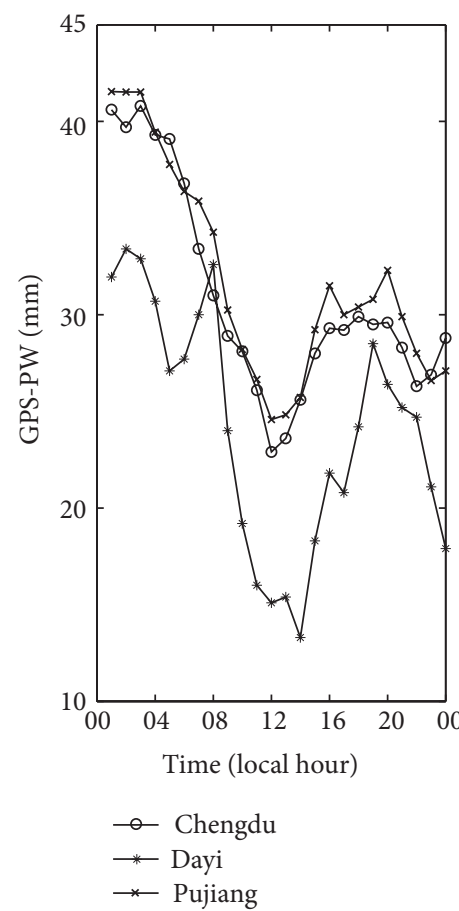

(c)

Figure 7: GPS-PW values recorded at Chengdu, Dayi, and Pujiang stations on July (a) 16, (b) 17, and (c) 18, 2010.

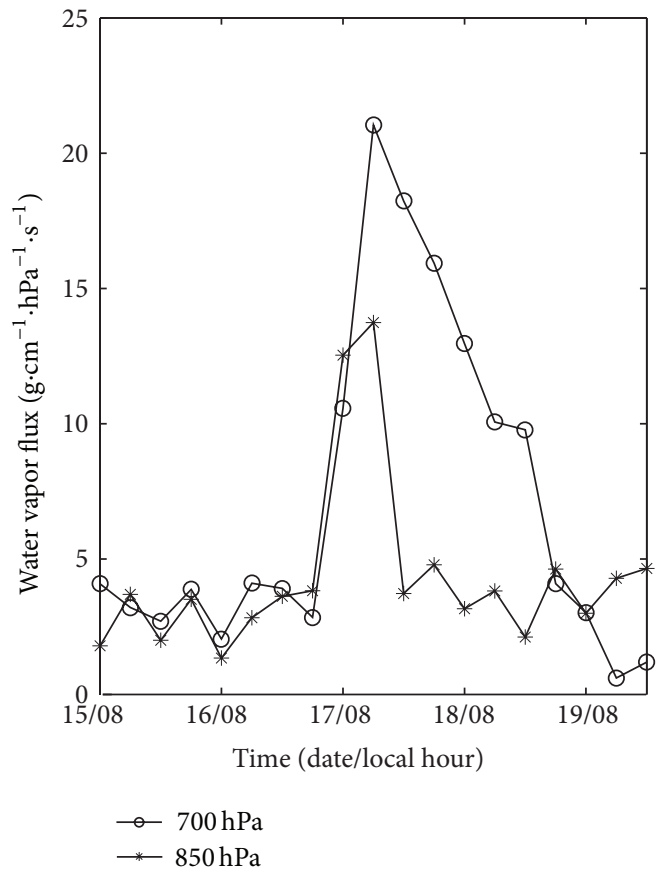

(a)

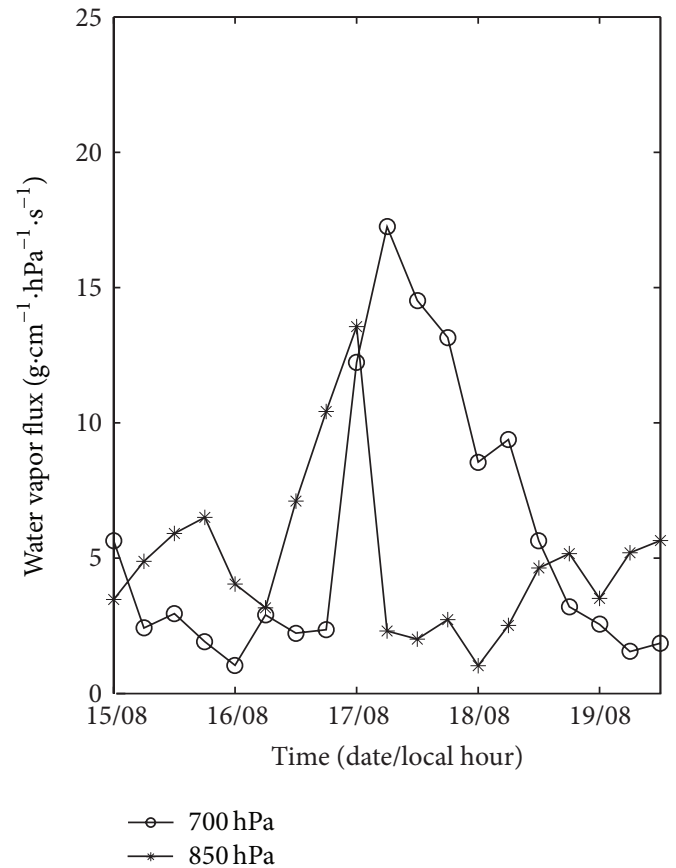

(b)

Figure 8: Evolution of water vapor flux recorded on July 15-18, 2010, at (a) Pujiang and (b) Chengdu stations $\left(\right.$ unit: $\mathrm{g} \cdot \mathrm{cm}^{-1} \cdot \mathrm{hPa}{ }^{-1} \cdot \mathrm{s}^{-1}$ ). 


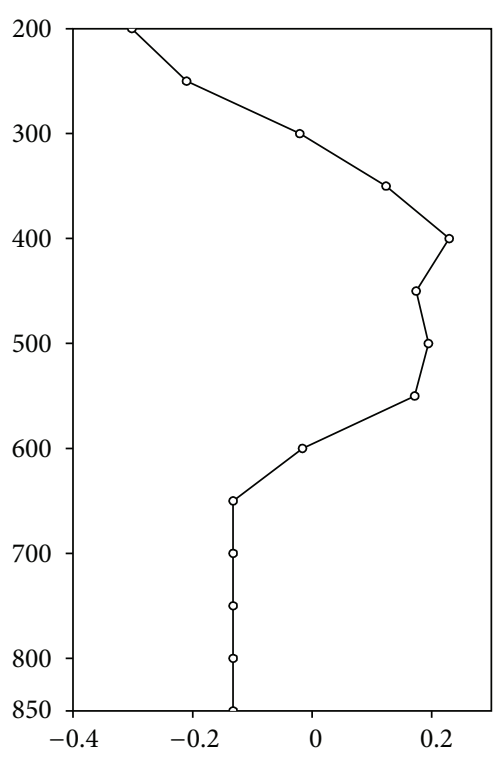

(a)

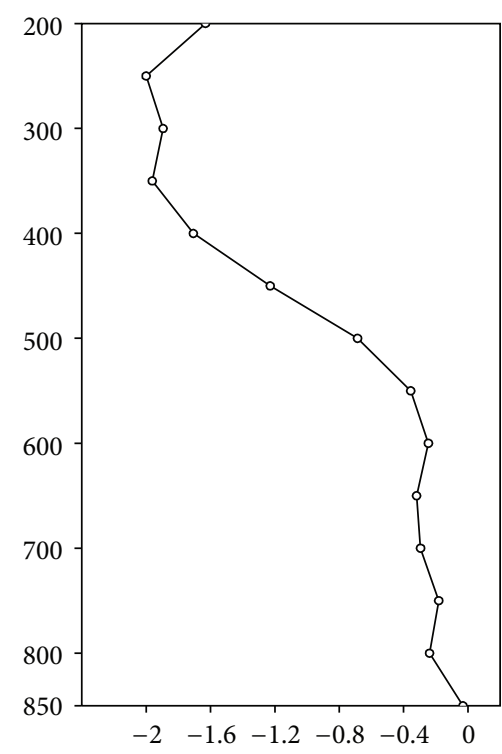

(b)

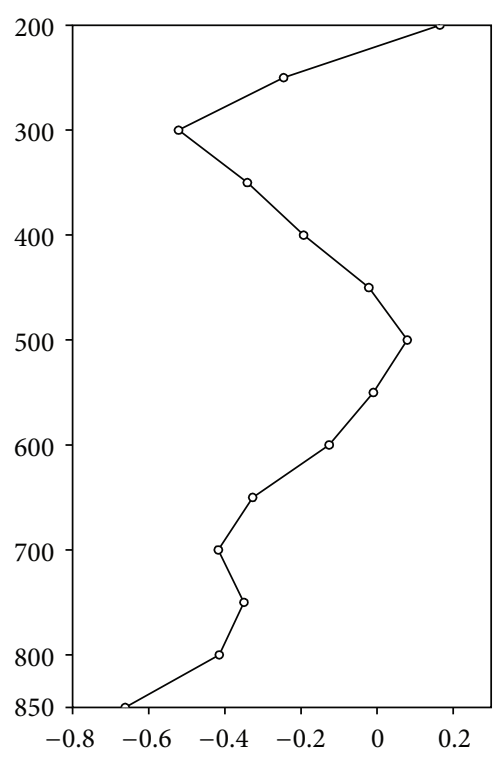

(c)

FIgURE 9: Profiles of the vertical velocity at the SWV center recorded at various times. (a) 20:00 on July 16, (b) 08:00 on July 17, and (c) 20:00 on July 17, 2010 (unit: $\mathrm{hPa} \cdot \mathrm{s}^{-1}$ ).

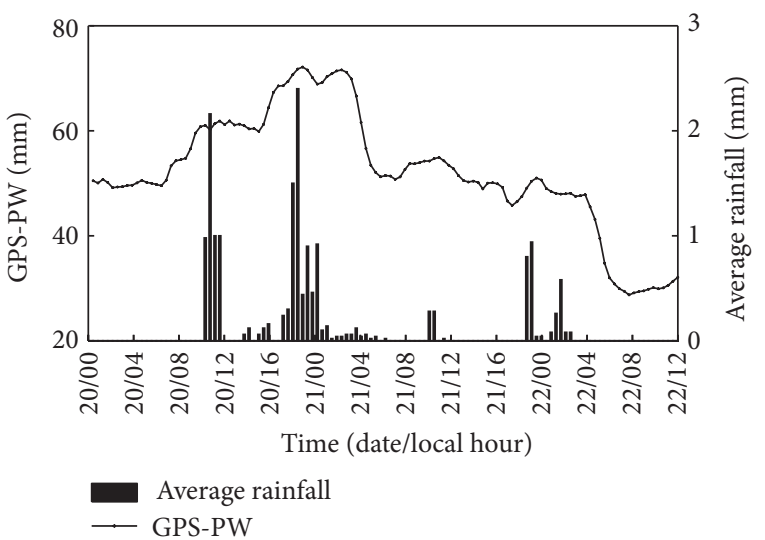

FIGURE 10: Temporal series of the average value of GPS-PW and regional average precipitation recorded on July 20-22, 2008, in Chengdu Plain at Chengdu, Dayi, Jintang, Pujiang, and Longquanyi stations.

increased slowly and reached a high value of $61.8 \mathrm{~mm}$ at 13:00 with a rate of increase at $1.2 \mathrm{~mm} / 0.5 \mathrm{~h}$. The rainfall occurred approximately $5 \mathrm{~h}$ after this increase. During the eastward movement of the TPV, the GPS-PW decreased slowly, increased again at 17:00, and reached its maximum of $72.1 \mathrm{~mm}$ at 21:30 20. At the same time, low-pressure circulation was induced at a low level over the western Sichuan Basin, which developed quickly to form the SWV. Subsequently, the GPSPW increased with fluctuation and reached a second high value of $71.5 \mathrm{~mm}$ at $01: 30$ on July 21 . It should be noted that the peak of the two rainfall processes occurred approximately $1 \mathrm{~h}$ before and after that of the GPS-PW. The GPS-PW increased to its high value through the coupling process, during which time the rainfall at the second stage was greater than that during the first. The high value of GPS-PW was distributed from noon to nighttime on July 20 and during the early morning of July 21, as indicated by Figures 10 and 11, which is consistent with the west to east movement of the vortex and its rain. Figure 11 shows that the value of GPS-PW was higher during the nighttime and lower during the day, which indicates that the high value of GPS-PW was necessary for the rainfall to occur.

3.3.3. Comparison of GPS-PW and Physical Element Fields. As shown in Figure 12, the water vapor flux at $850 \mathrm{hPa}$ increased slightly from $08: 00$ to 20:00 on July 20 , which was caused by the weak southwestward airflow over the basin during formation of the TPV. During the first stage of rainfall, the peak of GPS-PW occurred approximately $7 \mathrm{~h}$ prior to that of the water vapor flux. At 08:00 on July 21, the southwestward wind near the basin strengthened; the SWV and the TPV coupled; and the water vapor flux of the Chengdu Plain reached $8 \mathrm{~g} \cdot \mathrm{cm}^{-1} \cdot \mathrm{hPa}^{-1} \cdot \mathrm{s}^{-1}$. At the same time, the second stage of the main rainfall occurred. The peak of GPS-PW occurred earlier than that of the water vapor flux. The water vapor flux then increased continuously and reached its maximum at $700 \mathrm{hPa}$ and $850 \mathrm{hPa}$ at 20:00. The humidity in the basin increased, and the rainfall increased significantly through the influence of the two vortices and the transfer of atmospheric water.

Figure 13 shows that at 20:00 on July 20 , the vertical velocity of vortex center at $32.5^{\circ} \mathrm{N}, 100.5^{\circ} \mathrm{E}$ descended below $550 \mathrm{hPa}$ before ascending between $550 \mathrm{hPa}$ and $300 \mathrm{hPa}$ and descending above $300 \mathrm{hPa}$. At 08:00 on July 21, the vertical motion of the vortex center at $31^{\circ} \mathrm{N}, 105^{\circ} \mathrm{E}$ was nearly completely opposite to that of the previous movement of descent 


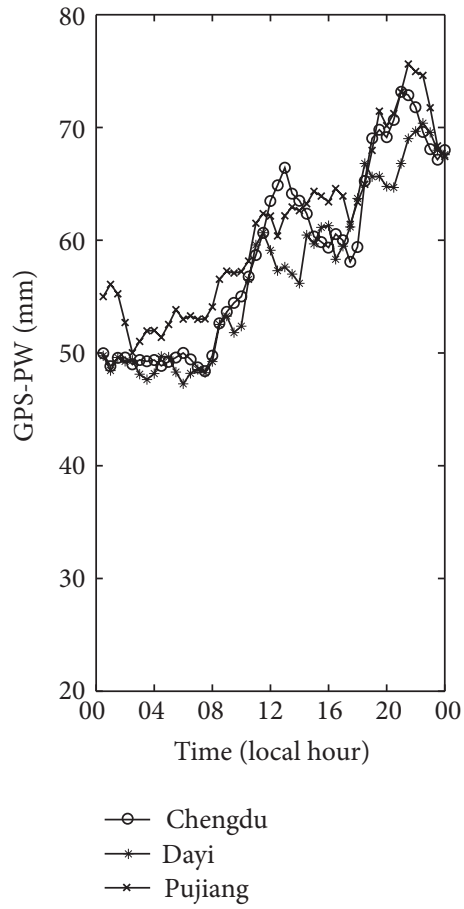

(a)

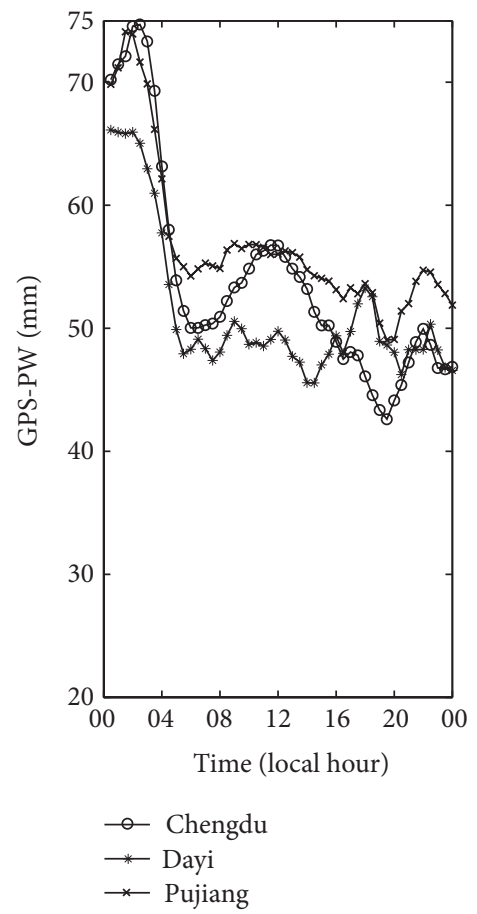

(b)

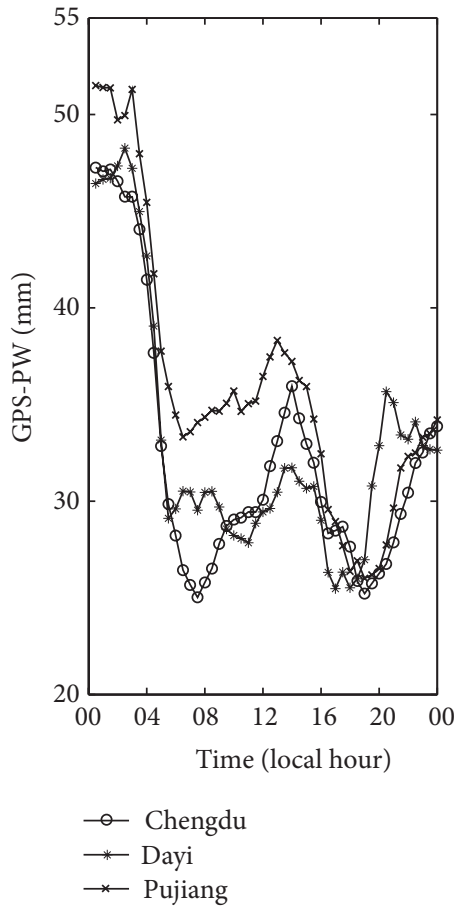

(c)

Figure 11: GPS-PW values recorded at Chengdu, Dayi, and Pujiang on July (a) 20, (b) July 21, and (c) July 22, 2008.

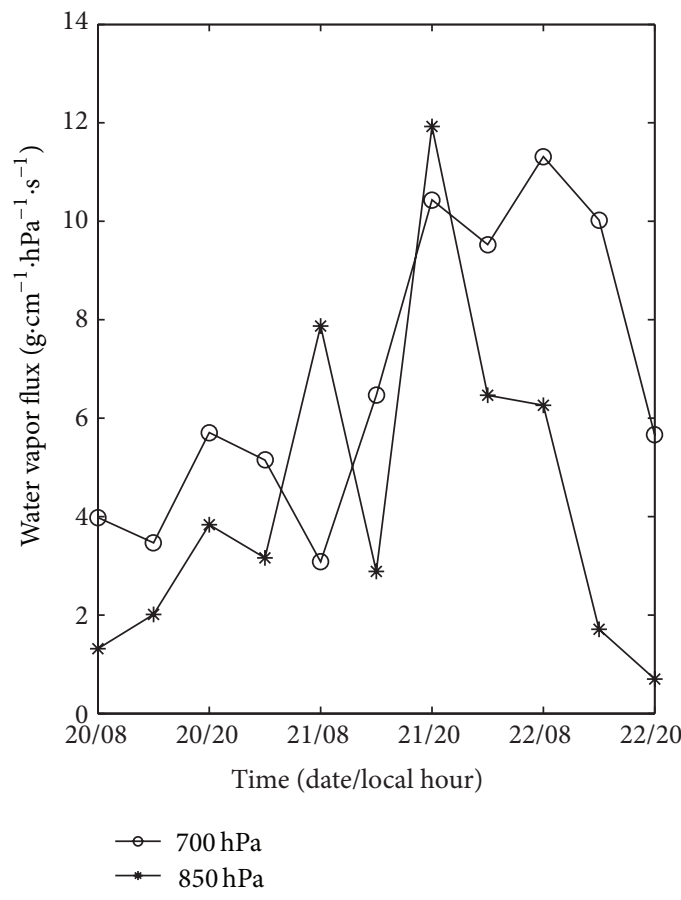

(a)

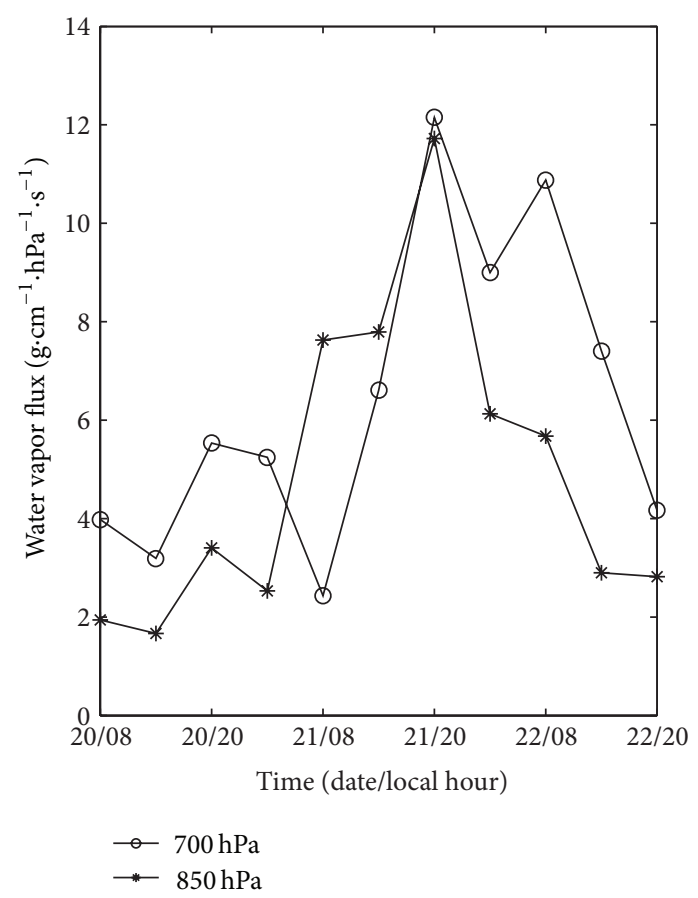

(b)

FIGURE 12: Evolution of water vapor flux recorded on July 20-22, 2008, at (a) Pujiang and (b) Chengdu stations $\left(\right.$ unit: $\mathrm{g} \cdot \mathrm{cm}^{-1} \cdot \mathrm{hPa}{ }^{-1} \cdot \mathrm{s}^{-1}$ ). 


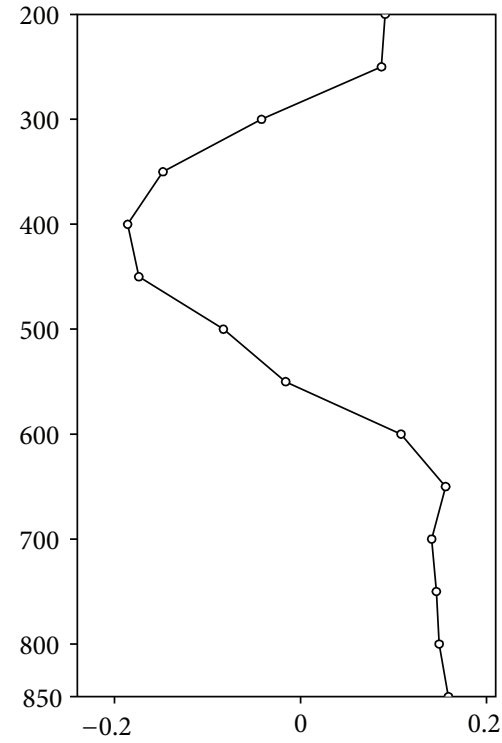

(a)

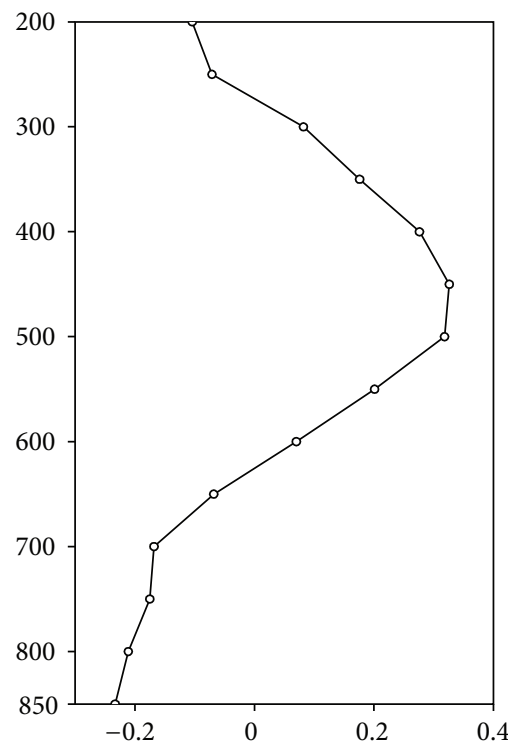

(b)

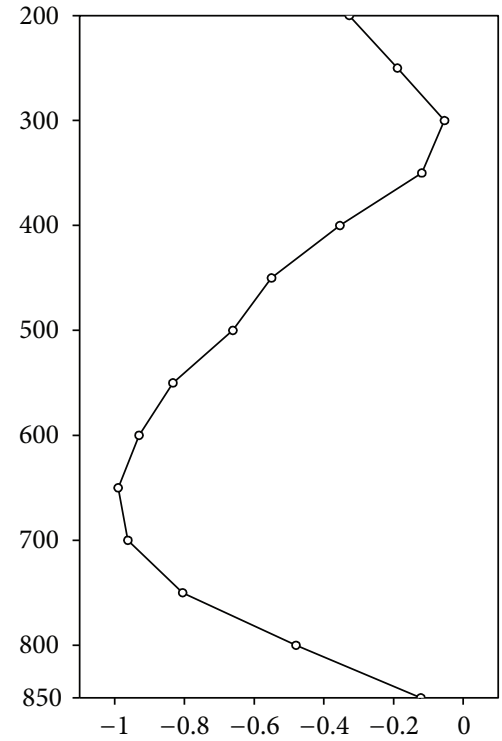

(c)

FIGURE 13: Profiles of the vertical velocity at the SWV center recorded at various times. (a) 20:00 on July 20, (b) 08:00 on July 21, and (c) 20:00 on July 21 (unit: $\mathrm{hPa} \cdot \mathrm{s}^{-1}$ ).

from $600 \mathrm{hPa}$ to $300 \mathrm{hPa}$. At that moment, the SWV formed in Sichuan Basin and coupled with the TPV, which strengthened the center of the SWV. At 20:00, it showed strong ascending motion from the low to high layers, and the maximum vertical velocity reached $-10 \times 10^{-1} \mathrm{hPa} \cdot \mathrm{s}^{-1}$. The GPSPW surged approximately $13 \mathrm{~h}$ prior to development of the SWV. However, the GPS-PW dropped to the level before the generation of SWV when SWV developed to the strongest. These results demonstrate that the increase of GPS-PW may indicate the development of the vortex for this case. However, additional cases should be tested to obtain definitive results.

\section{Conclusion and Discussion}

In this study, high-resolution precipitable water data obtained through ground-based GPS technology was used to analyze the heavy rain caused by various plateau weather systems. Three vortex-like rainstorms occurring in Sichuan Basin caused by the development and the eastward shift of the TPV and SWV in September 2007, July 2010, and July 2008 were analyzed comprehensively by using GPS-PW data derived through the GPS observation network of Chengdu Plain combined with routine meteorological observation data, intensive observation data, and reanalysis data. The results are summarized in the following points.

(1) GPS-PW increased before the development of TPV and SWV. Rainfall occurred mostly during high values of GPS-PW. The surge and drop of the GPSPW may indicate the beginning and the end of vortex rain, respectively, in some cases.

(2) During the process of rain caused by the TPV, the GPS-PW showed small fluctuation of its high value level, and the peak of rainfall occurred earlier or at nearly the same time as the GPS-PW. After that time, the GPS-PW maintained the changes with the amount of vortex dynamics elements and water vapor fluxes at each stage of rainfall development.

(3) In a specific case study, the increase in water was caused mainly by continuous southwestward airflow and the lifting of convergence during a rainfall process caused by SWV, which coincided with a larger fluctuation in GPS-PW values. When GPS-PW reached a certain level, rainfall commenced; however, the GPSPW decreased after rainfall. When the vortex circulation and water transfer remained constant, the GPSPW surged again, causing situations that are conducive to a new stage of rainfall. In this study, the peak of GPS-PW occurred earlier than that of the water vapor flux. The increase of GPS-PW occurred earlier than the generation of the vortex, and the vortex development lagged behind the maximum GPS-PW.

(4) During the process of rainfall caused by the TPV, which occurred on July 15-18, 2010, the GPS-PW maintained its high value before formation of the $S W V$, and the rainfall occurred after further increase in GPS-PW. This increase was significantly influenced and strengthened by the coupling of these two vortices. The peak of GPS-PW occurred earlier than that of the water flux, and the GPS-PW surged prior to development of the SWV. This supplement and increase in atmospheric water was highly beneficial for the development of low-level vortex circulation.

Finally, it should be noted that the characteristics of GPSPW and their correlation to atmospheric water were analyzed by using only three short periods of data in this study. Therefore, the behavior of GPS-PW shown in this paper may not 
be indicative of general patterns. It is necessary to research other TPV and SWV periods by using more data to further support the conclusions drawn in this study. The universal applicability of some of these conclusions should be fully tested and improved upon by additional cases and data, and the analysis of atmospheric energy should also be considered in comparison with physical element fields. Nevertheless, the results of this study can be used preliminarily to show that GPS-PW can be used as a new and useful tool for monitoring atmospheric water in weather analysis and forecasting over and near the TP. Thus, this study can enrich the scientific understanding of heavy rainstorms caused by the TPV and SWV, as well as upgrade the operational monitoring and forecasting of high-impact weather influenced by the TP.

\section{Conflict of Interests}

The authors declare that there is no conflict of interests regarding the publication of this paper.

\section{Acknowledgments}

The authors would like to express their sincere thanks to Ms. Jie Guo, Ms. Jiaona Chen, Dr. Hao Wang, Ms. Liping Hao, Ms. Na Xie, and the leadership of the Meteorological Bureau of Sichuan Province and Chengdu City for their valuable support for this study. This work was supported by the National Key Basic Research and Development Project of China (Grant no. 2012CB417202), the Special Fund for Meteorological Research in the Public Interest (Grant no. GYHY201206042), the National Natural Science Foundation of China (Grant nos. 41175045, U1133603), and the Key Research Projects of Chengdu Regional Meteorological Center of China Meteorological Administration (Grant nos. 2010-3, 2010-5).

\section{References}

[1] M. Bevis, S. Businger, T. A. Herring, C. Rocken, R. A. Anthes, and R. H. Ware, "GPS meteorology: remote sensing of atmospheric water vapor using the global positioning system," Journal of Geophysical Research, vol. 97, pp. 15787-15801, 1992.

[2] S. Marcus, J. Kim, T. Chin, D. Danielson, and J. Laber, "Influence of GPS precipitable water vapor retrievals on quantitative precipitation forecasting in Southern California," Journal of Applied Meteorology and Climatology, vol. 46, no. 11, pp. 18281839, 2007.

[3] S. Jin, Z. Li, and J. Cho, "Integrated water vapor field and multiscale variations over China from GPS measurements," Journal of Applied Meteorology and Climatology, vol. 47, no. 11, pp. 3008-3015, 2008.

[4] Y.-H. K. Ying-Hwa Kuo, Y.-R. G. Yong-Run Guo, and E. R. Westwater, "Assimilation of precipitable water measurements into a mesoscale numerical model," Monthly Weather Review, vol. 121, no. 4, pp. 1215-1238, 1993.

[5] C. Rocken, T. Hove, M. Johnson et al., "GPS/STORM-GPS sensing of atmospheric water vapor for meteorology," Journal of Atmospheric and Oceanic Technology, vol. 12, pp. 468-478, 1995.

[6] T. Iwabuchi, I. Naito, and N. Mannoji, "A comparison of Global Positioning System retrieved precipitable water vapor with the numerical weather prediction analysis data over the Japanese Islands," Journal of Geophysical Research D, vol. 105, no. 4, pp. 4573-4585, 2000.

[7] H. C. Baker, A. H. Dodson, N. T. Penna, M. Higgins, and D. Offiler, "Ground-based GPS water vapour estimation: potential for meteorological forecasting," Journal of Atmospheric and Solar-Terrestrial Physics, vol. 63, no. 12, pp. 1305-1314, 2001.

[8] G. Gendt, G. Dick, C. Reigber, M. Tomassini, Y. Liu, and M. Ramatschi, "Near real time GPS water vapor monitoring for numerical weather prediction in Germany," Journal of the Meteorological Society of Japan, vol. 82, no. 1B, pp. 361-370, 2004.

[9] S. de Haan, S. Barlag, H. K. Baltink, F. Debie, and H. van der Marel, "Synergetic use of GPS water vapor and meteosat images for synoptic weather forecasting," Journal of Applied Meteorology, vol. 43, no. 3, pp. 514-518, 2004.

[10] C. Li, J. Mao, J. Li, and Q. Xia, "Remote sensing precipitable water with GPS," Chinese Science Bulletin, vol. 44, no. 11, pp. 1041-1045, 1999.

[11] T. Sato and F. Kimura, "Diurnal cycle of convective instability around the Central Mountains in Japan during the warm season," Journal of the Atmospheric Sciences, vol. 62, no. 5, pp. 1626-1636, 2005.

[12] O. Okamura and F. Kimura, "Behavior of GPS-derived precipitable water vapor in the mountain lee after the passage of a cold front," Geophysical Research Letters, vol. 30, pp. 17-46, 2003.

[13] Y.-A. Liou and C.-Y. Huang, "GPS observations of PW during the passage of a typhoon," Earth, Planets and Space, vol. 52, no. 10, pp. 709-712, 2000.

[14] S.-Y. Ha, Y.-H. Kuo, Y.-R. Guo, C. Rocken, and T. Van Hove, "Comparison of GPS slant wet delay measurements with model simulations during the passage of a squall line," Geophysical Research Letters, vol. 29, pp. 2113-2116, 2002.

[15] G. Li, D. Huang, B. Liu, and J. Chen, "Experiment on driving precipitable water vaport from ground-based GPS network in Chengdu Plain," Geo-Spatial Information Science, vol. 10, no. 3, pp. 181-185, 2007.

[16] Y.-H. Kuo, X. Zou, S. J. Chen et al., "A GPS/MET Sounding through an Intense Upper-Level Front," Bulletin of the American Meteorological Society, vol. 79, no. 4, pp. 617-626, 1998.

[17] H. Seko, S. Shimada, H. Nakamura, and T. Kato, “Threedimensional distribution of water vapor estimated from tropospheric delay of GPS data in a mesoscale precipitation system of the Baiu front," Earth, Planets and Space, vol. 52, no. 11, pp. 927933, 2000.

[18] S. De Haan, H. Van Der Marel, and S. Barlag, "Comparison of GPS slant delay measurements to a numerical model: case study of a cold front passage," Physics and Chemistry of the Earth, vol. 27, no. 4-5, pp. 317-322, 2002.

[19] C. Reigber, G. Gendt, G. Dick, and M. Tomassini, "Water vapor monitoring for weather forecasts," GPS World, vol. 13, no. 1, pp. $18-27,2002$.

[20] J. Morland and C. Mätzler, "Spatial interpolation of GPS integrated water vapour measurements made in the Swiss Alps," Meteorological Applications, vol. 14, no. 1, pp. 15-26, 2007.

[21] R. Eresmaa, M. Nordman, M. Poutanen, J. Syrjärinne, J.-P. Luntama, and H. Järvinen, "Parameterization of tropospheric delay correction for mobile GNSS positioning: a case study of a cold front passage," Meteorological Applications, vol. 15, no. 4, pp. 447-454, 2008. 
[22] R. A. Mazany, S. Businger, S. I. Gutman, and W. Roeder, "A lightning prediction index that utilizes GPS integrated precipitable water vapor," Weather and Forecasting, vol. 17, no. 5, pp. 1034-1047, 2002.

[23] K. Kehrer, B. Graf, and W. P. Roeder, "Global positioning system (GPS) precipitable water in forecasting lightning at spaceport canaveral," Weather and Forecasting, vol. 23, no. 2, pp. 219-232, 2008.

[24] H. Seko, H. Nakamura, Y. Shoji, and T. Iwabuchi, “The meso- $\gamma$ scale water vapor distribution associated with a thunderstorm calculated from a dense network of GPS receivers," Journal of the Meteorological Society of Japan, vol. 82, no. 1 B, pp. 569-586, 2004.

[25] R. Ohtani, "Detection of water vapor variations driven by thermally-induced local ciculations using the Japanese continuous GPS array," Geophysical Research Letters, vol. 28, no. 1, pp. 151-154, 2001.

[26] G. Li, F. Kimura, T. Sato, and D. Huang, "A composite analysis of diurnal cycle of GPS precipitable water vapor in central Japan during Calm Summer Days," Theoretical and Applied Climatology, vol. 92, no. 1-2, pp. 15-29, 2008.

[27] D. K. Adams, R. M. S. Fernandes, and J. M. F. Maia, "GNSS precipitable water vapor from an Amazonian rain forest flux tower," Journal of Atmospheric and Oceanic Technology, vol. 28, no. 10, pp. 1192-1198, 2011.

[28] J. Lee, J.-U. Park, J. Cho, J. Baek, and H. W. Kim, "A characteristic analysis of fog using GPS-derived integrated water vapour," Meteorological Applications, vol. 17, no. 4, pp. 463-473, 2010.

[29] D. M. James, "GPS Precipitable water as a diagnostic of the north American monsoon in California and Nevada," Journal of Climate, vol. 26, pp. 1432-1444, 2013.

[30] T. Takagi, F. Kimura, and S. Kono, "Diurnal variation of GPS precipitable water at Lhasa in premonsoon and monsoon periods," Journal of the Meteorological Society of Japan, vol. 78, no. 2, pp. 175-180, 2000.

[31] S. Pramualsakdikul, R. Haas, G. Elgered, and H.-G. Scherneck, "Sensing of diurnal and semi-diurnal variability in the water vapour content in the tropics using GPS measurements," Meteorological Applications, vol. 14, no. 4, pp. 403-412, 2007.

[32] B. Wang and I. Orlanski, "Study of a heavy rain vortex formed over the eastern flank of the Tibetan Plateau," Monthly Weather Review, vol. 115, no. 7, pp. 1370-1393, 1987.

[33] C.-P. Chang, L. Yi, and G. T.-J. Chen, "A numerical simulation of vortex development during the 1992 east Asian summer monsoon onset using the navy's regional model," Monthly Weather Review, vol. 128, no. 6, pp. 1604-1631, 2000.

[34] L. Chen and Z. Luo, "A preliminary study of the dynamics of eastward shifting cyclonic vortices," Advances in Atmospheric Sciences, vol. 20, no. 3, pp. 323-332, 2003.

[35] S. Gao and F. Ping, "An experiment study of lee vortex with large topography forcing," Chinese Science Bulletin, vol. 50, no. 3, pp. 248-255, 2005.

[36] R. Shen, E. R. Reiter, and J. F. Bresch, "Numerical simulation of the development of vortices over the Qinghai-Xizang (Tibet) Plateau," Meteorology and Atmospheric Physics, vol. 35, no. 1-2, pp. 70-95, 1986.

[37] W. W. Wei Wang, Y.-H. K. Ying-Hwa Kuo, and T. T. Warner, "A diabatically driven mesoscale vortex in the lee of the Tibetan Plateau," Monthly Weather Review, vol. 121, no. 9, pp. 2542-2561, 1993.
[38] G. Zhu and S. Chen, "Analysis and comparison of mesoscale convective systems over the Qinghai-Xizang (Tibetan) Plateau," Advances in Atmospheric Sciences, vol. 20, no. 3, pp. 311-322, 2003.

[39] L. Li, R. Zhang, and M. Wen, "Diagnostic analysis of the evolution mechanism for a vortex over the Tibetan Plateau in June 2008," Advances in Atmospheric Sciences, vol. 28, no. 4, pp. 797808, 2011.

[40] U. Hugentobler, S. Schaer, and P. Fridez, Bernese GPS software version 4.2, Astronomical Institute, University of Berne, 2001.

[41] J. Saastamoinen, "Atmospheric correction for the troposphere and stratosphere in radio ranging of satellites. The use of artificial satellites for geodesy," Geophysical Monograph Series, vol. 15, pp. 247-251, 1975.

[42] J. Guo, G. P. Li, and D. F. Huang, "The troposphere weighted average temperature and the local modeling in Sichuan-Chongqing region based on 40 years of radiosonde data," Journal of Wuhan University, vol. 33, pp. 43-46, 2008 (Chinese).

[43] T. B. Zhao, L. K. Ai, and J. M. Feng, "An intercomparison between NCEP reanalysis and observed data over China," Climatic and Environmental Research, vol. 9, pp. 278-294, 2004 (Chinese). 

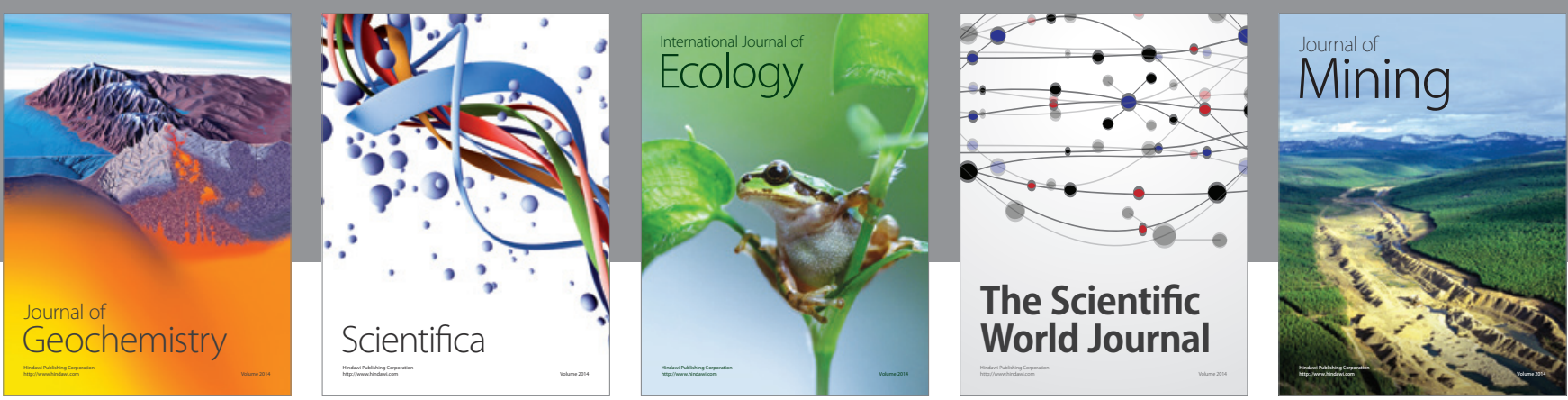

The Scientific World Journal
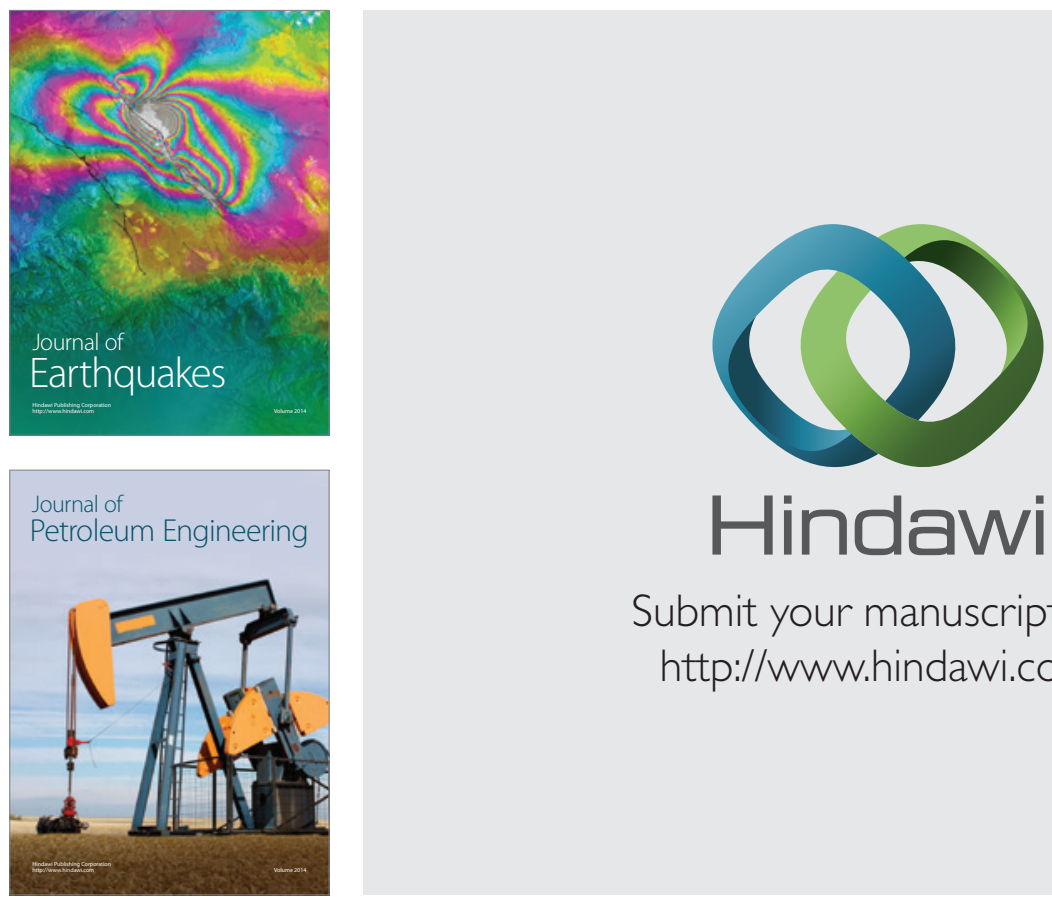

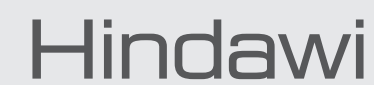

Submit your manuscripts at

http://www.hindawi.com
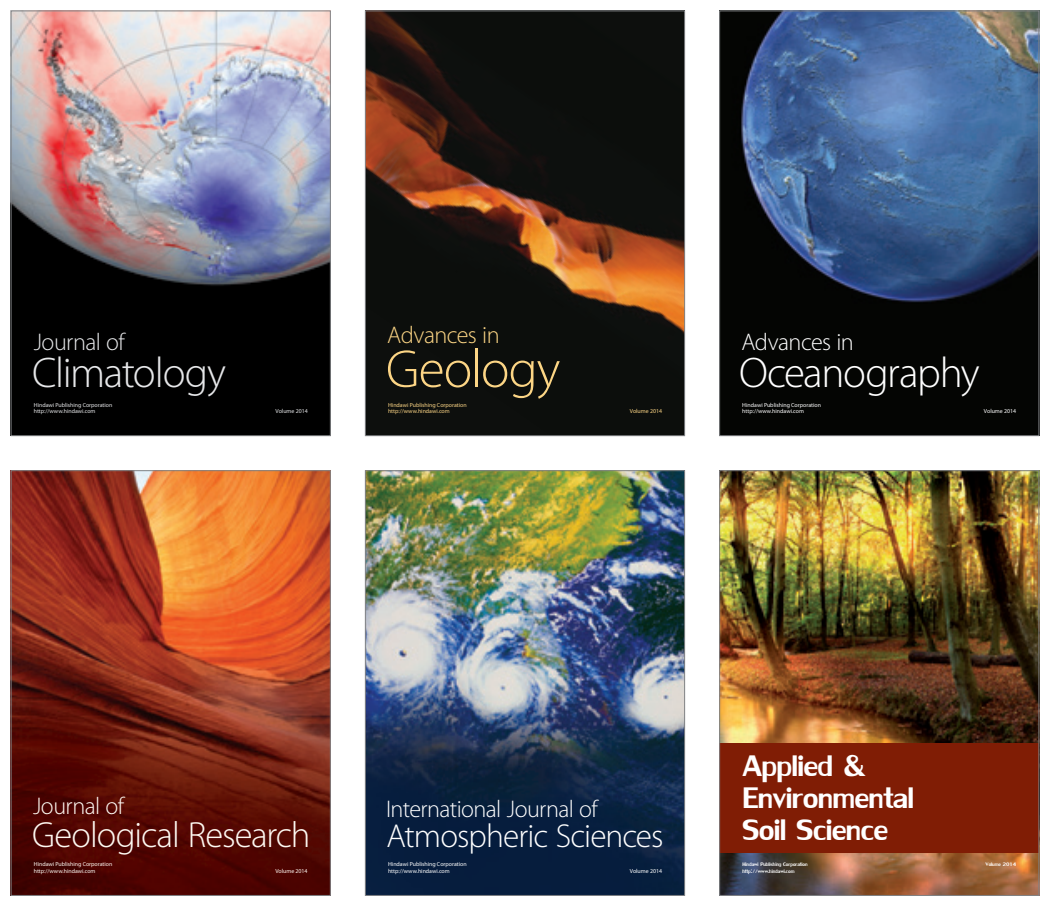
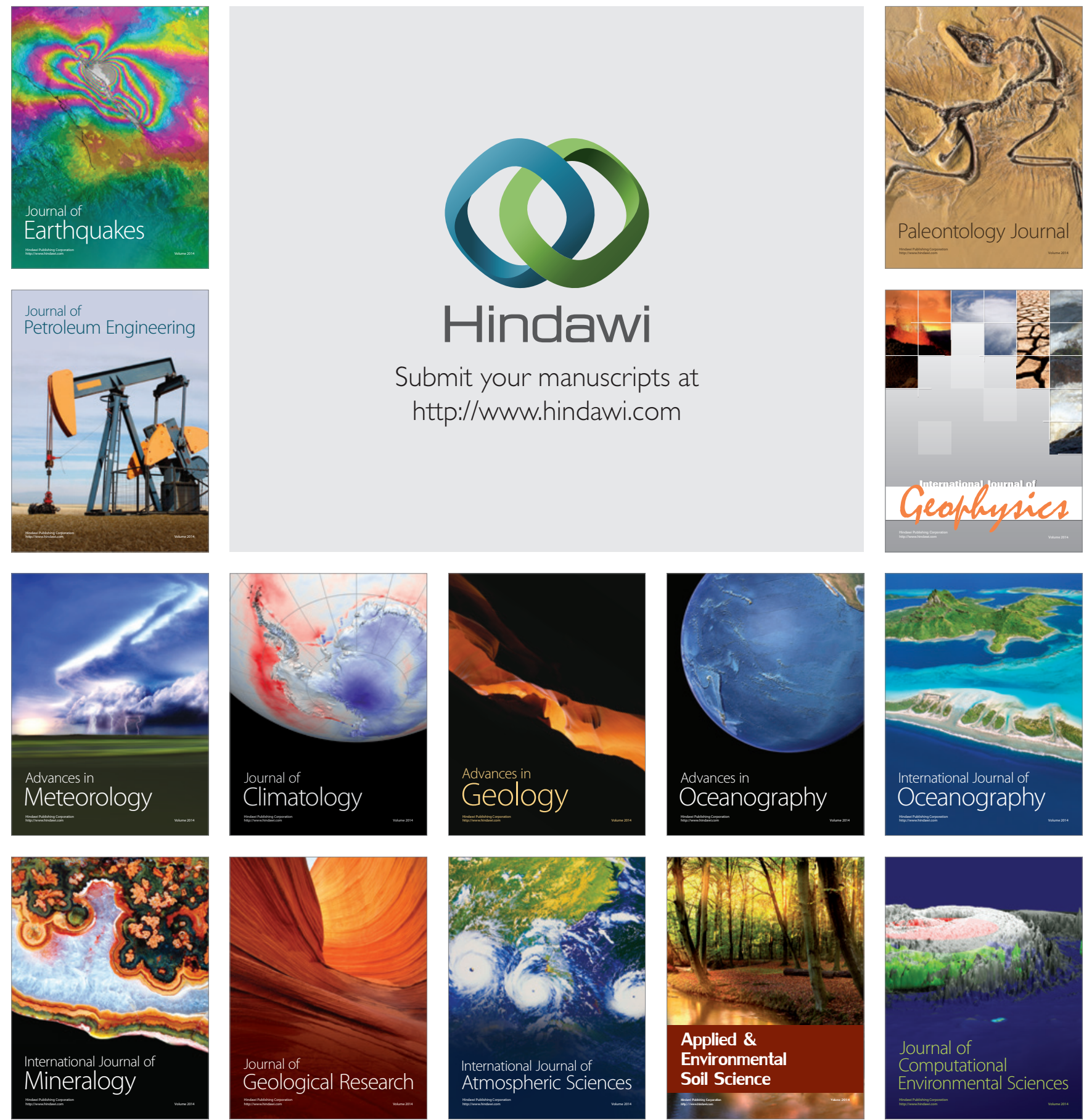